\title{
Triazolylthioacetamide: A Valid Scaffold for the Development of New Delhi Metallo- $\beta$-Lactmase-1 (NDM-1) Inhibitors
}

\author{
Le Zhai, ${ }^{\dagger \dagger, \perp}$ Yi-Lin Zhang, ${ }^{\dagger, \perp}$ Joon S. Kang, ${ }^{\S}$ Peter Oelschlaeger, ${ }^{\prime \prime}$ Lin Xiao, ${ }^{\dagger}$ Sha-Sha Nie, ${ }^{\dagger}$ \\ and $\mathrm{Ke}-\mathrm{Wu}$ Yang* ${ }^{*} \dagger$
}

${ }^{\dagger}$ Key Laboratory of Synthetic and Natural Functional Molecule Chemistry of Ministry of Education, College of Chemistry and Materials Science, Northwest University, Xi'an 710127, P. R. China

${ }^{\ddagger}$ College of Chemistry and Chemical Engineering, Baoji University of Arts and Sciences, Baoji 721016, P. R. China

${ }^{\S}$ Department of Biological Sciences, California State Polytechnic University, 3801 West Temple Avenue, Pomona, California 91768, United States

"Department of Pharmaceutical Sciences, College of Pharmacy, Western University of Health Sciences, 309 East Second Street, Pomona, California 91766, United States

Supporting Information

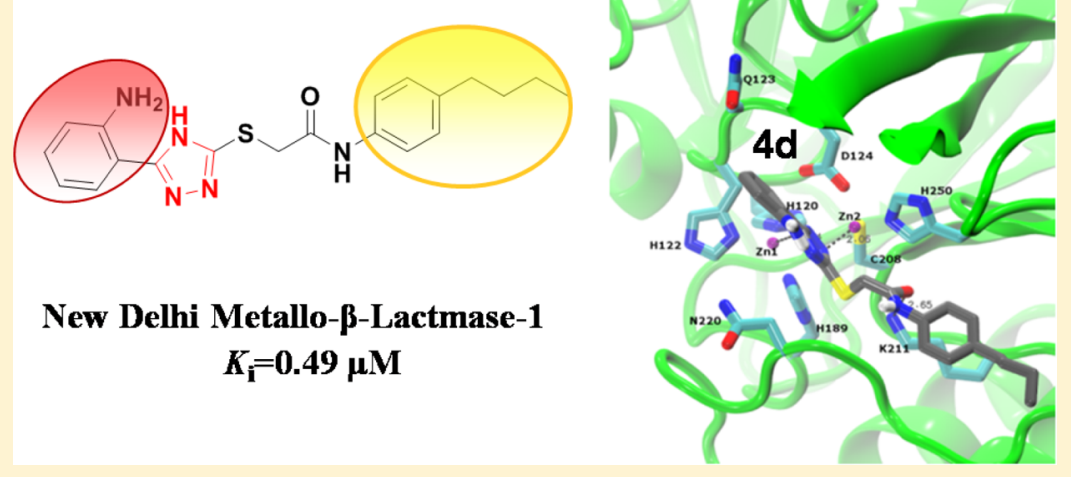

ABSTRACT: The metallo- $\beta$-lactamases $(\mathrm{M} \beta \mathrm{Ls})$ cleave the $\beta$-lactam ring of $\beta$-lactam antibiotics, conferring resistance against these drugs to bacteria. Twenty-four triazolylthioacetamides were prepared and evaluated as inhibitors of representatives of the three subclasses of $\mathrm{M} \beta$ Ls. All these compounds exhibited specific inhibitory activity against NDM- 1 with an IC $_{50}$ value range of 0.15-1.90 $\mu \mathrm{M}$, but no activity against CcrA, ImiS, and L1 at inhibitor concentrations of up to $10 \mu \mathrm{M}$. Compounds $4 \mathrm{~d}$ and $6 \mathrm{c}$ are partially mixed inhibitors with $K_{\mathrm{i}}$ values of 0.49 and $0.63 \mu \mathrm{M}$ using cefazolin as the substrate. Structure-activity relationship studies reveal that replacement of hydrogen on the aromatic ring by chlorine, heteroatoms, or alkyl groups can affect bioactivity, while leaving the aromatic ring of the triazolylthiols unmodified maintains the inhibitory potency. Docking studies reveal that the typical potent inhibitors of NDM-1, $4 \mathbf{d}$ and $\mathbf{6 c}$, form stable interactions in the active site of NDM-1, with the triazole bridging $\mathrm{Zn} 1$ and $\mathrm{Zn} 2$, and the amide interacting with Lys 211 (Lys224).

KEYWORDS: Metallo- $\beta$-lactamase, NDM-1, triazolylthioacetamide, inhibitor

$\mathrm{T}$ he emergence of antibiotic resistance is a global challenge for public health. To withstand $\beta$-lactam antibiotics, large numbers of pathogenic bacteria have evolved resistance. During the past decade, prevalence of antibiotic-resistant pathogens harboring mechanisms, such as reduced cell-wall permeability, efflux of antibiotics, and drug degradation mediated by $\beta$ lactamases, has become a major concern worldwide. $^{1-4} \beta$ Lactamases are enzymes that decompose $\beta$-lactam antibiotics by hydrolyzing the $\mathrm{C}-\mathrm{N}$ bond of their $\beta$-lactam ring. According to the Ambler convention, $\beta$-lactamases are grouped into four classes, $\mathrm{A}-\mathrm{D}$, based on their amino acid sequence homologies. ${ }^{5}$ Class $\mathrm{A}, \mathrm{C}$, and $\mathrm{D}$ enzymes comprise the serine $\beta$-lactamases, which utilize an active-site serine as a nucleophile. Class $\mathrm{B}$ enzymes are called metallo- $\beta$-lactamases $(\mathrm{M} \beta \mathrm{Ls})$, and these enzymes utilize either 1 or 2 equiv of $\mathrm{Zn}$ (II) to catalyze the $\beta$ lactam hydrolysis reaction. ${ }^{6-8} \mathrm{M} \beta$ Ls are able to promote the hydrolysis of a broad range of $\beta$-lactam antibiotics, including penicillins, cephalosporins, and carbapenems. ${ }^{9}$

$\mathrm{M} \beta \mathrm{Ls}$ are further divided into subclasses $\mathrm{B} 1-\mathrm{B} 3$, based on amino acid sequence homologies and $\mathrm{Zn}$ (II) content. ${ }^{10} \mathrm{New}$ Delhi metallo- $\beta$-lactmase-1 (NDM-1), a B1 subclass enzyme first discovered in $2008,{ }^{11}$ has become a global threat because it confers resistance to almost all $\beta$-lactam antibiotics and due to its rapid spread of the plasmid-encoded NDM-1 gene. ${ }^{12,13}$

Received: December 23, 2015

Accepted: February 16, 2016

Published: February 16, 2016 
The inhibitors of serine- $\beta$-lactamases (classes A, C, and D), such as tazobactam and sulbactam, have been used in combination with penicillins to treat infections with resistant bacteria. Novel effective $\mathrm{M} \beta \mathrm{L}$ inhibitors for such combination therapies are urgently needed. ${ }^{14-16}$ Marchand-Brynaert et al. reported a series of mercaptoacetic acid thiol ester derivatives as potent $\mathrm{M} \beta \mathrm{L}$ inhibitors, which provided a starting point for the design of sulfur-doped "pro-inhibitors". ${ }^{17}$ Subsequently, other sulfur-containing compounds, such as thiol carboxylates, ${ }^{18}$ thiols, ${ }^{19,20}$ and thiomandelic acid, ${ }^{21}$ were synthesized and evaluated. Thiomandelic acid was reported to be a broadspectrum inhibitor of $\mathrm{M} \beta \mathrm{Ls}$ with $K_{\mathrm{i}}$ values of $0.09 \mu \mathrm{M}$ for $R$ thiomandelic acid and $1.28 \mu \mathrm{M}$ for the $S$-isomer. Moreover, NMR assays pointed out that the thiol group of both $R$ - and $S$ thiomandelic acids was capable of binding to the two zinc ions in the active site. ${ }^{21}$ Faridoon et al. reported that 3-mercapto1,2,4-triazoles and $N$-acylated thiosemicarbazides exhibited moderate inhibitory activity against the $\mathrm{M} \beta \mathrm{L}$ IMP-1 from Pseudomonas aeruginosa with a mixed inhibition mode. ${ }^{22}$ Recently, our studies showed that the azolylthioacetamide compounds specifically inhibit $\mathrm{M} \beta \mathrm{L}$ ImiS (B2) and the most potent inhibitor exhibits an $\mathrm{IC}_{50}$ value of $70 \mathrm{nM}^{23}$ All tested amino acid thioester derivatives are very potent inhibitors of $\mathrm{L} 1$ (B3), exhibiting an $\mathrm{IC}_{50}$ value range of $0.018-2.9 \mu \mathrm{M}^{24}$ These thiol esters can release mercaptoacetic acid, which may form a disulfide bond to the active-site cysteine residue or coordinate $\mathrm{Zn}(\mathrm{II})$, thereby inactivating the enzyme. ${ }^{17} \mathrm{~N}$-Heterocyclic dicarboxylic acids are inhibitors of $\mathrm{M} \beta \mathrm{Ls}^{25}$ and the diarylsubstituted azolylthioacetamides exhibit broad-spectrum inhibitory activity against the $\mathrm{M} \beta \mathrm{Ls} \mathrm{L} 1, \mathrm{ImiS}$, and NDM-1 (B1). ${ }^{26}$ The information gained in our previous studies suggests that the triazolylthioacetamide is a valid scaffold for the development of NDM-1 inhibitors. Therefore, in this work a series of triazolylthioacetamides (shown in Figure 1) were synthesized, characterized, and evaluated against $\mathrm{M} \beta \mathrm{Ls}$.
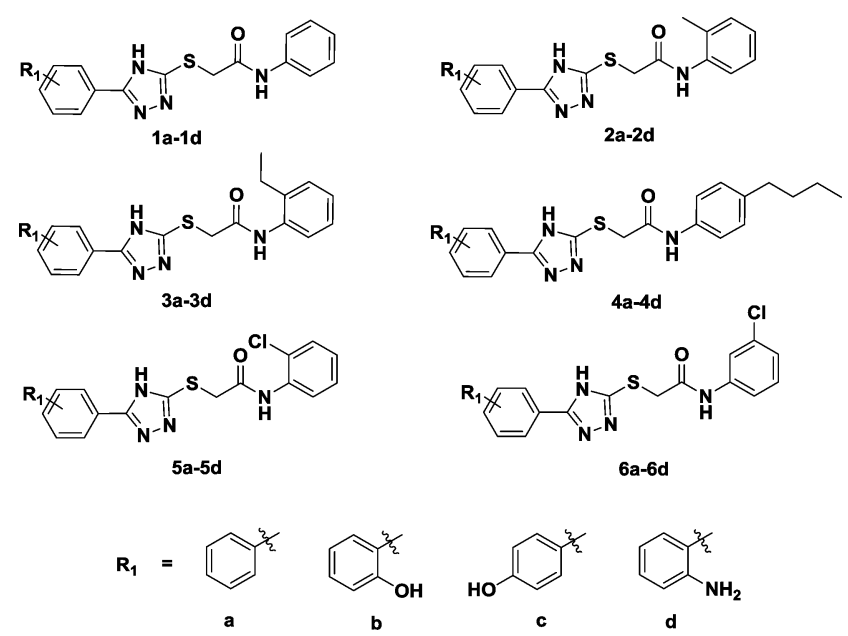

Figure 1. Structures of the triazolylthioacetamides.

Twenty-four triazolylthioacetamides were synthesized as shown in Scheme 1. Briefly, $N$-substituted 2-chloroacetamides (1-6) were first prepared by acylation between substituted anilines and chloroacetyl chloride. 5-Substituted-4H-1,2,4triazole-3-thiols (a-d) were prepared in three steps. ${ }^{22}$ Methyl arylcarboxylates (s2) were prepared by esterifying correlative substituted benzoic acids (s1) and were then converted into benzoylhydrazine (s3) by condensing with hydrazine. The
Scheme 1. Synthetic Route of Triazolylthioacetamides

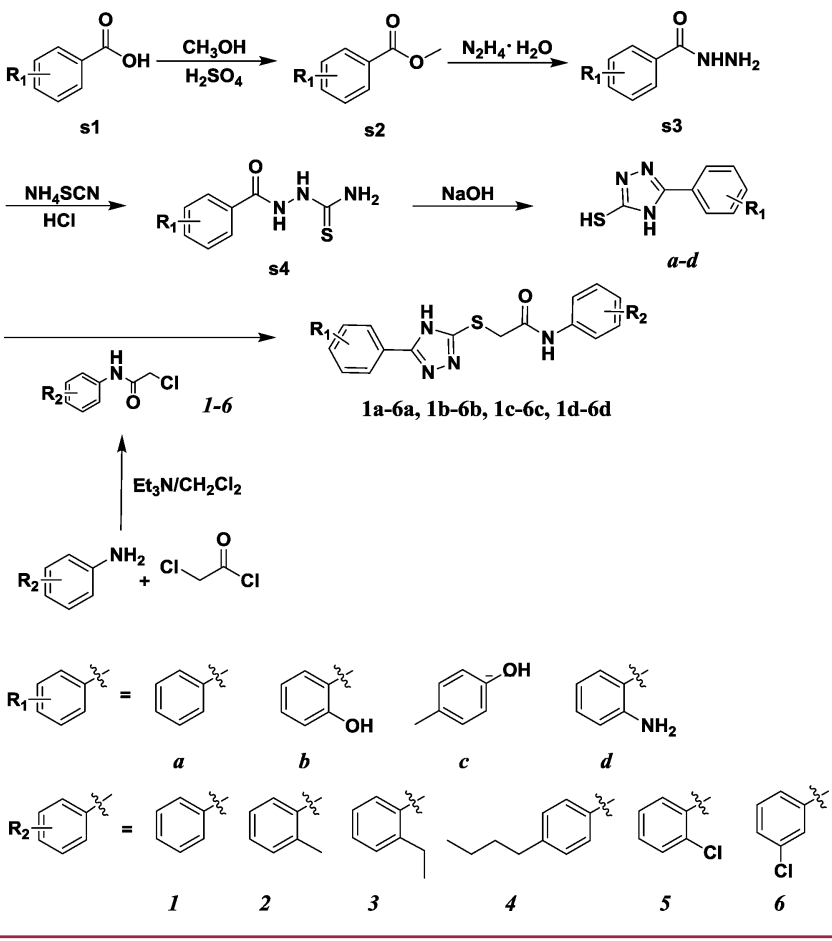

benzoylhydrazines reacted with $\mathrm{NH}_{4} \mathrm{SCN}$ under acid conditions to give correlative aroylthioureas (s4), which were converted into the substituted triazolylthiols $(\mathbf{a}-\mathbf{d})$ at reflux in the presence of sodium hydroxide. Finally, the target triazolylthioacetamides were generated by a nucleophilic substitution reaction under alkaline conditions. ${ }^{27}$

To test whether these triazolylthioacetamides were specific or even broad-spectrum inhibitors of the $\mathrm{M} \beta \mathrm{Ls}, \mathrm{M} \beta \mathrm{Ls}$ from subclasses B1a (CcrA), B1b (NDM-1), B2 (ImiS), and B3 (L1) were overexpressed and purified as previously described. ${ }^{28-31}$ In vitro, the inhibitory activities of all compounds prepared were tested against the $\mathrm{M} \beta \mathrm{Ls}$ on an Agilent UV8453 spectrometer as described by Bush et al., using cefazolin (imipenem for ImiS) as the substrate. ${ }^{32}$ The substrate concentrations were varied between 26 and $160 \mu \mathrm{M}$, and inhibitor concentrations were varied between $15 \mathrm{nM}$ and $10 \mu \mathrm{M}$. Enzyme and inhibitor were preincubated for $60 \mathrm{~min}$ before starting the kinetic experiments. The inhibitor concentrations causing 50\% decrease of enzyme activity $\left(\mathrm{IC}_{50}\right)$ was calculated based on the kinetic data. The inhibition constants $\left(K_{\mathrm{i}}\right)$ were determined by plotting the kinetic data for slope and intercept versus substrate concentration. The inhibitory mode was identified by generating Lineweaver-Burk plots of the data.

The inhibition studies indicated that the triazolylthioacetamides had specific inhibitory activity against NDM-1, but no activity was observed against CcrA, ImiS, and L1 at inhibitor concentrations of up to $10 \mu \mathrm{M}$. The inhibitor concentrations causing $50 \%$ decrease of enzyme activity $\left(\mathrm{IC}_{50}\right)$ of triazolylthioacetamides against NDM-1 are presented in Table 1. Clearly, triazolylthioacetamides 1-6a, 1-6b, 2c, 4-6c, 1d, and 3-6d exhibited high inhibitory activities against NDM-1 with $\mathrm{IC}_{50}$ values of less than $1 \mu \mathrm{M}$, while $\mathbf{1 c}, 3 \mathbf{c}$, and $\mathbf{2 d}$ showed a slightly higher $\mathrm{IC}_{50}$ value range of $1.2-1.9 \mu \mathrm{M}$. In particular, $\mathbf{1 a}, \mathbf{4 a}, \mathbf{2 b}$, $4 \mathbf{b}, 4 \mathrm{~d}$, and $\mathbf{6 b}$ showed the lowest $\mathrm{IC}_{50}$ values around $0.15 \mu \mathrm{M}$. We previously tested the intermediates aryltriazolyl mercaptans as inhibitors of NDM-1, and the results showed that these 
Table 1. IC $_{50}$ Values of Triazolylthioacetamides against NDM-1

\begin{tabular}{|c|c|c|c|c|c|c|c|}
\hline compd & $\mathrm{IC}_{50}(\mu \mathrm{M})$ & compd & $\mathrm{IC}_{50}(\mu \mathrm{M})$ & compd & $\mathrm{IC}_{50}(\mu \mathrm{M})$ & compd & $\mathrm{IC}_{50}(\mu \mathrm{M})$ \\
\hline 1a & $0.17 \pm 0.04$ & $1 b$ & $0.42 \pm 0.07$ & 1c & $1.2 \pm 0.1$ & $1 d$ & $0.33 \pm 0.05$ \\
\hline $2 a$ & $0.19 \pm 0.07$ & $2 b$ & $0.16 \pm 0.05$ & $2 c$ & $0.98 \pm 0.09$ & $2 d$ & $1.9 \pm 0.1$ \\
\hline $3 a$ & $0.99 \pm 0.03$ & $3 b$ & $0.93 \pm 0.08$ & $3 c$ & $1.5 \pm 0.1$ & $3 d$ & $0.45 \pm 0.03$ \\
\hline $4 a$ & $0.15 \pm 0.07$ & $4 b$ & $0.16 \pm 0.03$ & $4 c$ & $0.48 \pm 0.05$ & $4 d$ & $0.16 \pm 0.04$ \\
\hline $5 a$ & $0.35 \pm 0.05$ & $5 b$ & $0.98 \pm 0.06$ & $5 c$ & $0.52 \pm 0.03$ & $5 d$ & $0.61 \pm 0.02$ \\
\hline $6 a$ & $0.69 \pm 0.08$ & $6 b$ & $0.16 \pm 0.02$ & $6 c$ & $0.37 \pm 0.04$ & $6 d$ & $0.23 \pm 0.04$ \\
\hline
\end{tabular}

intermediates have no inhibitory activity against the enzyme. Within this series of new inhibitors, comparison of their potencies reveals that in the presence of the triazole ring, most substitutions did not alter their potency against NDM-1 significantly. While the hydroxyl substitution on the 4-position $(\mathbf{1}-\mathbf{6 c})$ of the aromatic ring of the triazolylthiols diminishes the potency against the enzyme slightly on average, compounds with no substitution (1a, 2a, 4a, and 5a) exhibited the highest potency. Furthermore, replacement of a hydrogen at the 2position of the aromatic ring of phenylacetamide with a methyl group (2d) or an ethyl group (3a and $\mathbf{3 b}$ ) reduces potency. Dramatically, replacing the 2-position hydrogen $(\mathbf{1} \mathbf{a}-\mathbf{d})$ with chlorine $(\mathbf{5 a}-\mathbf{d})$ does not change their activities significantly. The presence of a butyl group at the 4-position $(4 a-d)$ of the phenylacetamide increased the potency against NDM-1. Moving the chlorine from the 2- $(\mathbf{5 a}-\mathbf{d})$ to the 3-position $(6 \mathbf{a}-\mathbf{d})$ also had a favorable effect, except for $\mathbf{6 a}$.

To further identify the inhibition mode of these $\mathrm{M} \beta \mathrm{L}$ inhibitors, typical representatives $\mathbf{4 d}$ and $\mathbf{6 c}$ were chosen to determine $K_{\mathrm{i}}$ values. Lineweaver-Burk plots of NDM-1 catalyzed hydrolysis of cefazolin in the absence and presence of inhibitors are displayed in Figure 2. Compounds $4 d$ and $6 c$ exhibited $K_{\mathrm{i}}$ values of 0.49 and $0.63 \mu \mathrm{M}$, respectively, which are slightly larger than their correlative $\mathrm{IC}_{50}$ values $(0.16$ and 0.37 $\mu \mathrm{M}$, respectively). The analysis also demonstrated that both of the compounds employed the same partially mixed inhibition type.

Molecular docking and its analysis (refer to Supporting Information for details) resulted in clusters of 31 and five comparable conformations (out of 50) docked into the NDM-1 active site with average binding energies of -7.2 and $-8.0 \mathrm{kcal} /$ mol for $\mathbf{4 d}$ and $\mathbf{6 c}$, respectively. The conformations displayed in Figure 3 are the lowest-energy conformations within these clusters with binding energies of -7.7 and $-8.6 \mathrm{kcal} / \mathrm{mol}$ for $4 \mathrm{~d}$ and $6 c$, respectively.

The docking studies reveal that in compounds $4 \mathbf{d}$ and $\mathbf{6 c}$ the triazole coordinate at $\mathrm{Zn} 1$ and $\mathrm{Zn} 2$ of NDM-1 at comparable distances, which leads to nearly superimposable conformations, as can be seen in Figure 3A. In addition, they both interact with Lys211 (Lys224 according to standard numbering ${ }^{10}$ ) via the amide carbonyl group at distances of less than $3 \AA$. The hydroxyl group of compound $6 \mathrm{c}$ makes an additional interaction with $\mathrm{Gln} 123$ (Gln119), which may contribute to the almost $1 \mathrm{kcal} / \mathrm{mol}$ more favorable binding energy relative to 4d. This difference is not in agreement with experiments, though, where 4d was more potent; in reality the hydroxyl might interact with solvent instead of Gln123 (Gln119). Comparable to previous findings, ${ }^{23,24}$ the triazole ring of these compounds plays an important role in the interactions with active site $\mathrm{Zn}(\mathrm{II}) \mathrm{s}$, while the close interaction with the conserved Lys211 (Lys224) is also observed.

It was interesting to observe that the compounds had no activity against CcrA, even though the active sites of NDM-1
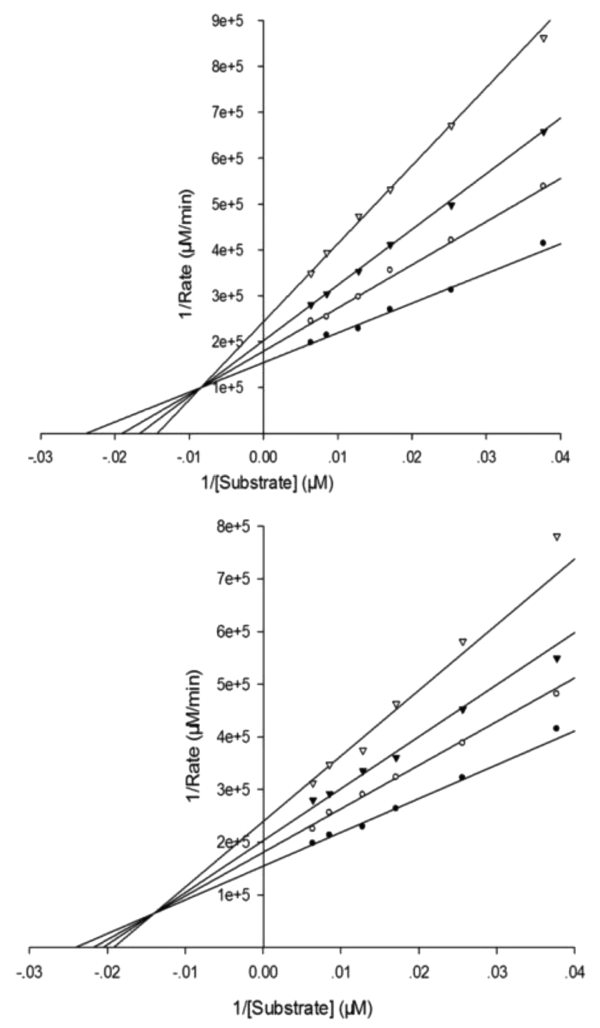

Figure 2. Lineweaver-Burk plot of NDM-1 catalyzed hydrolysis of cefazolin in the absence and presence of $4 \mathrm{~d}$ (up) and $\mathbf{6 c}$ (down). Inhibitor concentrations were $0 \mu \mathrm{M}(\bullet), 0.25 \mu \mathrm{M}(\bigcirc), 0.5 \mu \mathrm{M}(\boldsymbol{\nabla})$, and $1.0 \mu \mathrm{M}(\nabla)$.

and CcrA are quite similar. There are two differences between the enzymes that may be significant for inhibitor binding: (1) CcrA has a glycine at position 119 , which is glutamine in NDM-1 and interacts with the hydroxyl group of $6 \mathrm{c}$. With glycine, no such interaction is possible in CcrA. (2) The distance between $\mathrm{Zn} 2$ and Lys224 is bigger in CcrA $(6.8 \AA)^{35}$ than in NDM-1 (5.3 $\AA$, PDB code 4HL2). Thus, it is possible that simultaneous interaction between the triazole ring and the $\mathrm{Zn}$ (II) ions and between the carbonyl and Lys211 (Lys224) is more effective in NDM-1. Accordingly, docking studies with $4 \mathrm{~d}$ and $6 c$ to CcrA revealed that the binding energies were less favorable than in NDM-1 with mean binding energies of the corresponding and most populated clusters of $-6.9 \mathrm{kcal} / \mathrm{mol}$ for both molecules. Unlike in NDM-1, there was no difference between the two molecules, which may be explained by the missing interaction between $6 \mathrm{c}$ and residue 119 in CcrA, and the distance between the carbonyl and Lys 224 was above $3 \AA$ in both cases, while coordination of the $\mathrm{Zn}$ (II) ions by the triazole ring was maintained. Combined, these observations argue that Lys211 (Lys224) cannot be too distant from the $\mathrm{Zn}$ (II) ions for effective inhibitor binding. 
A

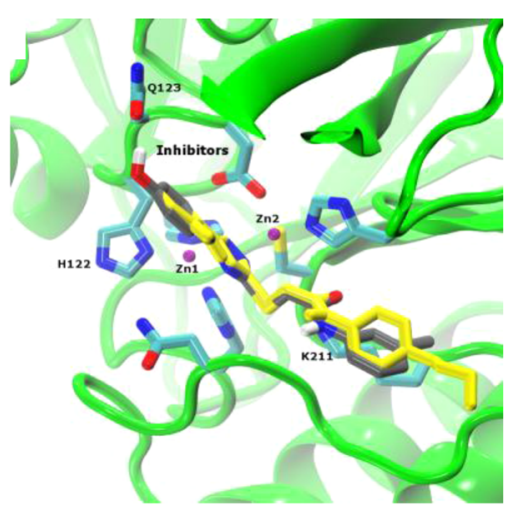

$\mathrm{B}$

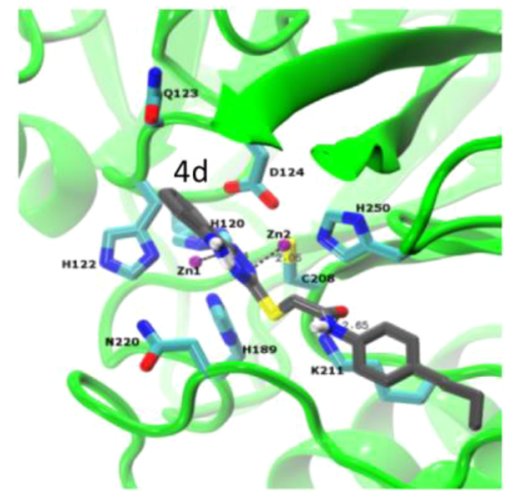

C

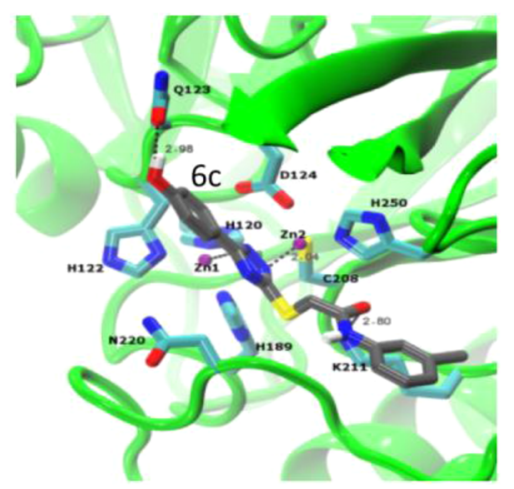

Figure 3. Low energy conformations of $\mathbf{4 d}$ and $\mathbf{6 c}$ docked into the active site of NDM-1 (PDB code $4 \mathrm{HL}_{2}^{33}$ ). The enzyme backbone is shown as cartoon in green, and selected residue side chains are shown as sticks colored by atom ( $\mathrm{C}$, cyan; $\mathrm{N}$, blue; $\mathrm{O}$, red; $\mathrm{S}$, yellow). The $\mathrm{Zn}$ (II) ions are shown as purple spheres. (A) Superimposition of compounds $4 \mathrm{~d}$ and $\mathbf{6 c}$ in the NDM-1 active site. Compound $6 \mathrm{c}$ is depicted as sticks colored by atom (same colors as for protein residues except $C$ in gray), and $\mathbf{4 d}$ as yellow sticks. (B,C) Detailed views of $\mathbf{4 d}$ and $\mathbf{6 c}$, respectively, displaying key enzyme residues and indicating interactions between the inhibitors and enzyme residues with dashed lines. Panels A-C were generated with VMD. ${ }^{34}$

In summary, 24 triazolylthioacetamides were synthesized and a general method was devised to develop various triazolylthioacetamides as $\mathrm{M} \beta \mathrm{L}$ inhibitors. In vitro biological activity assay revealed that the triazolylthioacetamides displayed partially mixed inhibition activity against NDM-1, with an $\mathrm{IC}_{50}$ values range of $0.15-1.90 \mu \mathrm{M}$. The analysis of the structure-activity relationship reveals that replacement of hydrogen on the aromatic ring by either chlorine or alkyl group can apparently have bioactivity consequences and suggests that the 4-position of the phenylacetamide plays a more significant role than the 2position. Moreover, leaving the aromatic ring of the triazolylthiols unmodified resulted in highest potency of the compounds. The work presented here has identified 24 potential partially mixed inhibitors for inhibition studies on NDM-1. Docking studies reveal that $\mathbf{4 d}$ and $\mathbf{6 c}$, as typical potent NDM-1 inhibitors, form stable interactions in the active site of NDM-1, with the triazole bridging $\mathrm{Zn} 1$ and $\mathrm{Zn} 2$, and the amide interacting tightly with Lys211 (Lys224).

\section{ASSOCIATED CONTENT}

\section{S Supporting Information}

The Supporting Information is available free of charge on the ACS Publications website at DOI: 10.1021/acsmedchemlett.5b00495.

Detailed synthesis procedure, NMR and ESI mass data for all target compounds, the methods for enzyme expression and purification, assay of inhibitory activity, and docking study (PDF)

\section{AUTHOR INFORMATION}

\section{Corresponding Author}

*Tel/Fax: +8629-8153-5035. E-mail: kwyang@nwu.edu.cn.

\section{Author Contributions}

${ }^{\perp}$ These authors contributed equally to this work. The manuscript was written through contributions of all authors.

\section{Funding}

This work was supported by grants 81361138018,21272186 , and 21572179 (to K.W.Y.) from the National Natural Science Foundation of China.

\section{Notes}

The authors declare no competing financial interest.

\section{REFERENCES}

(1) Blair, J. M.; Webber, M. A.; Baylay, A. J.; Ogbolu, D. O.; Piddock, L. J. Molecular mechanisms of antibiotic resistance. Nat. Rev. Microbiol. 2015, 13, 42-51.

(2) Tang, S. S.; Apisarnthanarak, A.; Hsu, L. Y. Mechanisms of $\beta$ lactam antimicrobial resistance and epidemiology of major community- and healthcare-associated multidrug-resistant bacteria. Adv. Drug Delivery Rev. 2014, 78, 3-13.

(3) Hawkey, P. M. Multidrug-resistant Gram-negative bacteria: a product of globalization. J. Hosp. Infect.. 2015, 89, 241-7.

(4) Zavascki, A. P.; Bulitta, J. B.; Landersdorfer, C. B. Combination therapy for carbapenem-resistant Gram-negative bacteria. Expert Rev. Anti-Infect. Ther. 2013, 11, 1333-53.

(5) (a) Bush, K.; Jacoby, G. A. Updated functional classification of beta-lactamases. Antimicrob. Agents Chemother. 2010, 54, 969-76. (b) Bush, $\mathrm{K}$. The $\mathrm{ABCD}$ 's of $\beta$-lactamase nomenclature. J. Infect. Chemother. 2013, 19, 549-59.

(6) Bush, K. The ABCD's of $\beta$-lactamase nomenclature. J. Infect. Chemother. 2013, 19, 549-59.

(7) Karsisiotis, A. I.; Damblon, C. F.; Roberts, G. C. A variety of roles for versatile zinc in metallo- $\beta$ eta-lactamases. Metallomics. 2014, 6, 1181-97.

(8) Meini, M. R.; Llarrull, L. I.; Vila, A. J. Overcoming differences: The catalytic mechanism of metallo- $\beta$-lactamases. FEBS Lett. 2015, 589, 3419-32.

(9) Crowder, M. W.; Spencer, J.; Vila, A. J. Metallo- $\beta$-lactamases: novel weaponry for antibiotic resistance in bacteria. Acc. Chem. Res. 2006, 39, 721-8.

(10) Galleni, M.; Lamotte-Brasseur, J.; Rossolini, G. M.; Spencer, J.; Dideberg, O.; Frere, J. M. Standard numbering scheme for class B $\beta$ lactamases. Antimicrob. Agents Chemother. 2001, 45, 660-3.

(11) Yong, D.; Toleman, M. A.; Giske, C. G.; Cho, H. S.; Sundman, K.; Lee, K.; Walsh, T. R. Characterization of a new metallo- $\beta$-lactamase 
gene, bla(NDM-1), and a novel erythromycin esterase gene carried on a unique genetic structure in Klebsiella pneumoniae sequence type 14 from India. Antimicrob. Agents Chemother. 2009, 53, 5046-54.

(12) Liang, Z.; Li, L.; Wang, Y.; Chen, L.; Kong, X.; Hong, Y.; Lan, L.; Zheng, M.; Guang-Yang, C.; Liu, H.; Shen, X.; Luo, C.; Li, K. K.; Chen, K.; Jiang, H. Molecular basis of NDM-1, a new antibiotic resistance determinant. PLoS One 2011, 6, e23606.

(13) Yang, H.; Aitha, M.; Hetrick, A. M.; Richmond, T. K.; Tierney, D. L.; Crowder, M. W. Mechanistic and spectroscopic studies of metallo- $\beta$-lactamase NDM-1. Biochemistry 2012, 51, 3839-47.

(14) Toney, J. H.; Moloughney, J. G. Metallo- $\beta$-lactamase inhibitors: promise for the future? Curr. Opin. Investig. Drugs 2004, 5, 823-6.

(15) Drawz, S. M.; Bonomo, R. A. Three decades of $\beta$-lactamase inhibitors. Clin. Microbiol. Rev. 2010, 23, 160-201.

(16) Guo, Z.; Ma, S. Recent advances in the discovery of metallo- $\beta$ lactamase inhibitors for $\beta$-lactam antibiotic-resistant reversing agents. Curr. Drug Targets 2014, 15, 689-702.

(17) Payne, D. J.; Bateson, J. H.; Gasson, B. C.; Proctor, D.; Khushi, T.; Farmer, T. H.; Tolson, D. A.; Bell, D.; Skett, P. W.; Marshall, A. C.; Reid, R.; Ghosez, L.; Combret, Y.; Marchand-Brynaert, J. Inhibition of metallo- $\beta$-lactamases by a series of mercaptoacetic acid thiol ester derivatives. Antimicrob. Agents Chemother. 1997, 41, 135-40.

(18) Concha, N. O.; Janson, C. A.; Rowling, P.; Pearson, S.; Cheever, C. A.; Clarke, B. P.; Lewis, C.; Galleni, M.; Frere, J. M.; Payne, D. J.; Bateson, J. H.; Abdel-Meguid, S. S. Crystal structure of the IMP-1 metallo $\beta$-lactamase from Pseudomonas aeruginosa and its complex with a mercaptocarboxylate inhibitor: binding determinants of a potent, broad-spectrum inhibitor. Biochemistry 2000, 39, 4288-98.

(19) Siemann, S.; Clarke, A. J.; Viswanatha, T.; Dmitrienko, G. I. Thiols as classical and llow-binding inhibitors of IMP-1 and other binuclear metallo- $\beta$-lactamases. Biochemistry 2003, 42, 1673-83.

(20) Lienard, B. M.; Garau, G.; Horsfall, L.; Karsisiotis, A. I.; Damblon, C.; Lassaux, P.; Papamicael, C.; Roberts, G. C.; Galleni, M.; Dideberg, O.; Frere, J. M.; Schofield, C. J. Structural basis for the broad-spectrum inhibition of metallo- $\beta$-lactamases by thiol. Org. Biomol. Chem. 2008, 6, 2282-94.

(21) Mollard, C.; Moali, C.; Papamicael, C.; Damblon, C.; Vessilier, S.; Amicosante, G.; Schofield, C. J.; Galleni, M.; Frere, J. M.; Roberts, G. C. Thiomandelic acid, a broad spectrum inhibitor of Zinc $\beta$ lactamases: kinetic and spectroscopic studies. J. Biol. Chem. 2001, 276, 45015-23.

(22) Faridoon; Hussein, W. M.; Vella, P.; Islam, N. U.; Ollis, D. L.; Schenk, G.; McGeary, R. P. 3-Mercapto-1,2,4-triazoles and N-acylated thiosemicarbazides as metallo- $\beta$-lactamase inhibitors. Bioorg. Med. Chem. Lett. 2012, 22, 380-6.

(23) Yang, S. K.; Kang, J. S.; Oelschlaeger, P.; Yang, K. W. Azolylthioacetamide: a highly promising scaffold for the development of metallo- $\beta$-lactamase inhibitors. ACS Med. Chem. Lett. 2015, 6, 45560 .

(24) Liu, X. L.; Shi, Y.; Kang, J. S.; Oelschlaeger, P.; Yang, K. W. Amino acid thioester derivatives: a highly promising scaffold for the development of metallo- $\beta$-lactamase L1 inhibitors. ACS Med. Chem. Lett. 2015, 6, 660-4.

(25) Feng, L.; Yang, K. W.; Zhou, L. S.; Xiao, J. M.; Yang, X.; Zhai, L.; Zhang, Y. L.; Crowder, M. W. N-heterocyclic dicarboxylic acids: broad-spectrum inhibitors of metallo- $\beta$-lactamases with co-antibacterial effect against antibiotic-resistant bacteria. Bioorg. Med. Chem. Lett. 2012, 22, 5185-9.

(26) Zhang, Y. L.; Yang, K. W.; Zhou, Y. J.; LaCuran, A. E.; Oelschlaeger, P.; Crowder, M. W. Diaryl-Substituted Azolylthioacetamides: Inhibitor Discovery of New Delhi Metallo- $\beta$-Lactamase1(NDM-1). ChemMedChem 2014, 9, 2445-8.

(27) Patel, R. V.; Patel, P. K.; Kumari, P.; Rajani, D. P.; Chikhalia, K. H. Synthesis of benzimidazolyl-1,3,4-oxadiazol-2ylthio-N-phenyl (benzothiazolyl) acetamides as antibacterial, antifungal and antituberculosis agents. Eur. J. Med. Chem. 2012, 53, 41-51.

(28) Wang, Z.; Benkovic, S. J. Purification, characterization, and kinetic studies of a soluble Bacteroides fragilis metallo- $\beta$-lactamase that provides multiple antibiotic resistance. J. Biol. Chem. 1998, 273, 22402-8.

(29) Yang, H.; Aitha, M.; Hetrick, A. M.; Richmond, T. K.; Tierney, D. L.; Crowder, M. W. Mechanistic and spectroscopic studies of metallo- $\beta$-lactamase NDM-1. Biochemistry 2012, 51, 3839-47.

(30) Crawford, P. A.; Sharma, N.; Chandrasekar, S.; Sigdel, T.; Walsh, T. R.; Spencer, J.; Crowder, M. W. Over-expression, purification, and characterization of metallo- $\beta$-lactamase ImiS from Aeromonas veronii bv. sobria. Protein Expression Purif. 2004, 36, $272-9$.

(31) Crowder, M. W.; Walsh, T. R.; Banovic, L.; Pettit, M.; Spencer, J. Overexpression, purification, and characterization of the cloned metallo- $\beta$-lactamase L1 from Stenotrophomonas maltophilia. Antimicrob. Agents Chemother. 1998, 42, 921-6.

(32) Bush, K.; Macalintal, C.; Rasmussen, B. A.; Lee, V. J.; Yang, Y. Kinetic interactions of Tazobactam with $\beta$-lactamases from all major structural classes. Antimicrob. Agents Chemother. 1993, 37, 851-8.

(33) Kim, Y.; Tesar, C.; Mire, J.; Jedrzejczak, R.; Binkowski, A.; Babnigg, G.; Sacchettini, J.; Joachimiak, A. Structure of apo- and monometalated forms of NDM-1-a highly potent carbapenemhydrolyzing metallo- $\beta$-lactamase. PLoS One 2011, 6, e24621.

(34) Humphrey, W.; Dalke, A.; Schulten, K. VMD: visual molecular dynamics. J. Mol. Graphics 1996, 14 (33-8), 27-8.

(35) Fitzgerald, P. M.; Wu, J. K.; Toney, J. H. Unanticipated inhibition of the metallo-b-lactamase from Bacteroides fragilis by 4 morpholineethanesulfonic acid (MES): a crystallographic study at 1.85 Å resolution. Biochemistry 1998, 37, 6791-800. 